\title{
Elaboration and characterization of a new activated carbon obtained from oregano residue: Application in environmental field
}

\author{
N. Oumam ${ }^{1}$, M. Oumam², A.K. Abourriche ${ }^{3}$, A.M. Abourriche ${ }^{1}$, H. Hannache ${ }^{2}$ \\ and A. Bennamara ${ }^{1}$ \\ ${ }^{1}$ Laboratoire des Biomolécules et Synthèse Organique, Université Hassan II-Mohammedia, Faculté des \\ Sciences Ben M'Sik, BP. 7955, Casablanca, Morocco \\ ${ }^{2}$ Équipe des Matériaux Thermo-Structuraux et Polymères/ Laboratoire de Recherche Subatomique et \\ Application, Université Hassan II-Mohammedia, Faculté des Sciences Ben M'Sik, BP. 7955, Casablanca, \\ Morocco \\ ${ }^{3}$ Laboratoire, Matériaux, Procédés, Environnement et Qualité, École Nationale des Sciences Appliquées, \\ BP. 63, 46000 Safi, Morocco
}

\begin{abstract}
This study focuses on the valorization of extraction residues of medicinal plants which represent approximately $80 \%$ of the gross weight of the plant. In this context we proceeded to the transformation of "marc oregano" to a material adsorbent type activated carbon. The oregano marc, obtained after extraction of essential oils and organic compounds, has undergone a chemical activation using the phosphoric acid $85 \%\left(\mathrm{H}_{3} \mathrm{PO}_{4}\right)$. It is well known as precursors of lignocellulosic activating agent, allows the development of a large porosity in the activated material. The activated product has subsequently underwent heat treatment in the temperature range from 200 to $350{ }^{\circ} \mathrm{C}$. The optimum temperature for development was set at $300^{\circ} \mathrm{C}$. The results obtained showed that the adsorbent material $\mathrm{O}_{300}$ has developed the interesting textural properties. It is an adsorbent material like activated carbon, which presents, according to the BET method, a specific surface of $1200 \mathrm{~m}^{2} \cdot \mathrm{g}^{-1}$ (specific surface area of commercial activated carbon is of about $905 \mathrm{~m}^{2} \cdot \mathrm{g}^{-1}$ ). The application of adsorbent material developed $\mathrm{O}_{300}$ in microbial decontamination of urban waste water, has revealed its effectiveness and its important adsorptive properties against pathogens pollutants from wastewater.
\end{abstract}

\section{INTRODUCTION}

Morocco has very significant potentials in the field of medicinal and aromatic plants (MAP). Currently, it perfoms the important productions of the MAP and their derivatives, which gives it a significant place in the international market. Among these we distinguish the plant of oregano which is widely used in cosmetic, pharmaceutical and food industries thanks to the flavoring, antimicrobial and antioxidant properties [1-3].

However, the extraction residues obtained from the MAP, which represent over $80 \%$ of the weight of the plant are not yet exploited. Which requires a valorization of these residues by opening a new way of exploiting these natural resources, and the transformation of these residues at activated carbon and applying it in the environmental field. It is within this context that fits the present work which has set its objectives itself: The valuation of oregano extract residues and its transformation into adsorbent material, and application of the material developed in the field of microbial decontamination of liquid effluents urban.

Activated carbons can be produced from a number of lignocellulosic precursor materials including: nuts olive, palm, peach and apricot [4,5], sawdust [6] and nut shells [7]. They are exposed to different activation methods in order to achieve a material with better adsorbent properties. The chemical activation using phosphoric acid $\left(\mathrm{H}_{3} \mathrm{PO}_{4}\right)$ is widely used for lignocellulosic precursors [8, 9]. By its acid action it intervenes as catalyst of the dehydration, it can also be promoter of separation between cellulose and lignin degradation agent and units of cellulose [10]. In addition to its role as inhibitor of carbon oxidation, phosphoric acid plays a catalytic role in the dehydration reaction. By its curing agent, it also promotes the development of a three-dimensional structure with a high porosity and with a very high specific surface.

\section{CHEMICAL ACTIVATION PROCESS OF OREGANO MARC}

The chemical activation process was conducted in the following experimental conditions: A mass of marc oregano $(\mathbf{O})$ was mixed with phosphoric acid at different proportions. Kneading the mixture is performed at room temperature. The resulting mixture is heat-treated under air at different temperatures: 200, 250, 300 and $350{ }^{\circ} \mathrm{C}$. Materials elaborated from oregano are called: $\mathbf{O}_{\mathbf{2 0 0}}, \mathbf{O}_{\mathbf{2 5 0}}$, $\mathbf{O}_{350}$ and $\mathbf{O}_{300}$ (numbers 200, 250, 300 and 350 indicate the temperature of treatment). The samples were then washed with water and then dried at $110^{\circ} \mathrm{C}$. The products obtained were ground and stored until used. The optimization of operating conditions showed that the mass ratio marc oregano/ $\mathrm{H}_{3} \mathrm{PO}_{4}$ is equal to 1 and the temperature $300^{\circ} \mathrm{C}$ are optimal conditions for preparation of activated carbon.

\section{CHARACTERIZATION OF THE OBTAINED MATERIALS}

\section{1. (DTA/TGA) analyses of the oregano marc}

In order to study the thermal behavior of studied precursor and to determine the temperature range of 


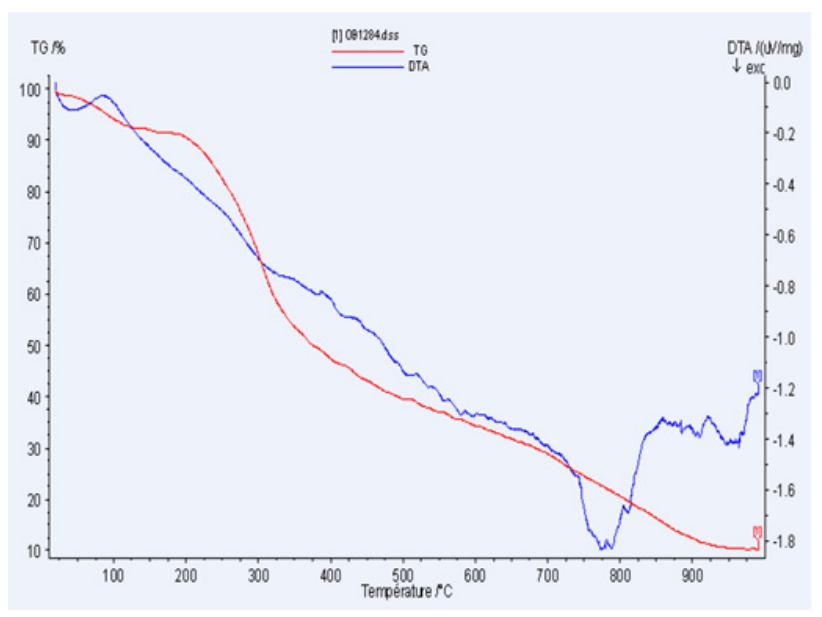

Figure 1. Thermal curves of the oregano $\operatorname{marc}(\mathbf{O})$.

Table 1. Elemental analysis of the the oregano marc $(\mathbf{O})$ and elaborated materials.

\begin{tabular}{lccccc}
\hline Atomic \% & $(\mathbf{O})$ & $\mathbf{O}_{\mathbf{2 0 0}}$ & $\mathbf{O}_{\mathbf{2 5 0}}$ & $\mathbf{O}_{\mathbf{3 0 0}}$ & $\mathbf{O}_{\mathbf{3 5 0}}$ \\
\hline Carbon & 39 & 50.44 & 56.68 & 65.48 & 56.86 \\
Oxygen & 5.44 & 4.02 & 3.30 & 2.44 & 2.13 \\
Hydrogen & 38.59 & 28.13 & 24.92 & 15.69 & 15.96 \\
\hline
\end{tabular}

activation, we performed a thermogravimetric analysis (DTA/TGA). The thermal and thermogravimetric analyses were carried out under argon flow with a Netzsch STA 409 apparatus. Samples of about $15 \mathrm{mg}$ were heated from room temperature to $1000^{\circ} \mathrm{C}$ at a heating rate of $10^{\circ} \mathrm{C} \cdot \mathrm{min}^{-1}$.

According to the thermogram of Figure 1, relative to oregano marc we observe three weight losses: The first, between $25^{\circ} \mathrm{C}$ and $140^{\circ} \mathrm{C}$, corresponds to the dehydration of oregano marc between 25 and $140^{\circ} \mathrm{C}$. The second loss, which has a peak at around $300^{\circ} \mathrm{C}$, is due to the departure of volatile molecules $\left(\mathrm{CO}, \mathrm{CO}_{2}\right.$ and $\left.\mathrm{CH}_{4} \ldots\right)$ during reorganizations and transformations of organic molecules. The third loss corresponds to the pyrolysis of residual carbon.

\subsection{Elemental analysis}

Elemental analysis was performed to determine the contents of carbon, hydrogen and oxygen, that are the main constituents of activated carbon. This analysis was conducted for oregano marc named "O" and the adsorbent materials prepared at different temperatures. The results obtained are reported in Table 1.

The results mentioned in the Table 1 show that oregano marc is relatively rich in organic carbon, which allows being a good precursor for the preparation of activated carbon. The results also show the effect of temperature treatment on the levels of hydrogen and oxygen, which decreases with increasing temperature.

The atomic percentage of carbon increases in the material elaborated until the temperature of $300{ }^{\circ} \mathrm{C}$, then decreases beyond this temperature because of pyrolysis reactions that take place in the material subject to a higher

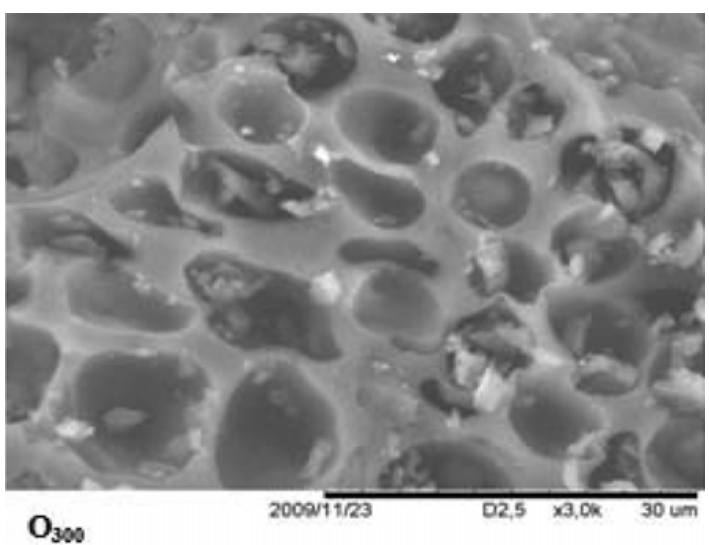

Figure 2. SEM micrograph of sample sintered at $300^{\circ} \mathrm{C}\left(\mathbf{O}_{\mathbf{3 0 0}}\right)$.

temperature and which allow a rearrangement of carbon skeleton during the heat treatment.

\subsection{Specific surface area}

The specific surface area of $\mathbf{O}_{\mathbf{3 0 0}}$ material was determined based on the BET method. The measurements of adsorption and desorption were performed in an apparatus type Micromeritics ASAP 2010.

The highly developed specific surface area obtained by chemical activation of oregano marc and mainly that of elaborated material at $300^{\circ} \mathrm{C}$, shows the effectiveness of phosphoric acid and heat treatment in the opening of the porosity and improvement of the specific surface area of this product.

The sample obtained at $300{ }^{\circ} \mathrm{C}\left(\mathbf{O}_{\mathbf{3 0 0}}\right)$ present a large surface area which is of about $1200 \mathrm{~m}^{2} \mathrm{~g}^{-1}$. This value is higher than that of commercial activated carbon which has a surface of about $905 \mathrm{~m}^{2} \mathrm{~g}^{-1}$.

\subsection{Determination of porosity and morphology of the obtained materials}

The porosity and distribution of the pore size of each material were determined by mercury intrusion porosimetry. The apparatus used was of type IV 9500 Micrometrics Autopore.

The results obtained from the material studied, are reported in Table 2.

Table 2. Porosity of sample sintered at $300{ }^{\circ} \mathrm{C}$.

\begin{tabular}{lc}
\hline Sample & $\mathbf{O}_{\mathbf{3 0 0}}$ \\
\hline Average pore diameter $(\mathrm{nm})$ & 15.2 \\
\hline Porosity (\%) & 53.29 \\
\hline
\end{tabular}

The internal porosity of the material is estimated at $\mathbf{O}_{\mathbf{3 0 0}} 53.29 \%$. This material is characterized by the presence of mesopores. The texture of the adsorbent material is represented by scanning electron microscopy (SEM) shown in the Figure 2.

The Scanning Electron Micrograph shows that the activation of the cellulosic precursor in the presence of phosphoric acid followed by heat treatment has a 
significant influence on the morphology of the obtained materials. The result showed a surface with rough morphological structure. The sample sintered at $300^{\circ} \mathrm{C}$ show highly porous structure.

\section{APPLICATION OF ADSORBENT MATERIAL $\mathrm{O}_{300}$ IN THE MICROBIAL DECONTAMINATION OF WASTEWATER}

Previous studies [11] showed that the bacteria adhere to solid supports prepared from carbon materials. In this context, we tested the effect of the material adsorbent $\mathbf{O}_{\mathbf{3 0 0}}$ against fecal coliform content in the wastewater of urban discharges. We proceeded to a filtration through a column charged with the material adsorbent $\mathbf{O}_{\mathbf{3 0 0}}$. The number of bacteria in the polluted wastewater tested was estimated at $10^{11}(\mathrm{CFU} / \mathrm{ml})$. The filtered waters were then analyzed and compared with the starting samples and also with filtered samples through a column charged with commercial activated carbon. The results show that treated wastewater by the material $\mathbf{O}_{\mathbf{3 0 0}}$ contain no bacteria $(0 \mathrm{CFU} / \mathrm{ml})$ contrary to those treated with Commercial Activated Carbon (CAC) that are still rich in bacteria pollutants $\left(6.4 .10^{4} \mathrm{CFU} / \mathrm{ml}\right)$. These interesting results show the effectiveness of the material $\mathbf{O}_{\mathbf{3 0 0}}$ against water microbial pollutants.

\section{CONCLUSIONS}

This study provides a new way of valorization of medicinal plants extraction residues by their transformation to adsorbent materials. The activated carbon obtained at $300{ }^{\circ} \mathrm{C}$ is characterized by a developed textural properties and an important specific area (about $1200 \mathrm{~m}^{2} \mathrm{~g}^{-1}$ ), which gives it a high adsorption capacity. The results obtained in the treatment of wastewater tested, showed that $\mathbf{O}_{\mathbf{3 0 0}}$ could be used as effective depolluting of wastewater thanks to these important adsorptive properties.

\section{References}

[1] J. Novak, B. Christina, J. Langbehn, F. Pank , M. Skoula, Y. Gotsiou and C.M. Franz, Biochem. Syst. Ecol, 28: 697-704, 2000.

[2] N. Aligiannis, E. Kalpoutzakis, S. Mitaku, and I. B. Chinou, Journal of Agriculture and Food Chemistry, 49: 4168-4170, 2001.

[3] F. Sahin, M. Gulluce, D. Daferera, A. Sokmen, M. Sokmen, M. Polissiou, G. Agar and H. Ozer, Food Control, Volume 15, Issue 7: 549-557, 2004.

[4] Carlos Monero-Castilla, Francisco Carrasco-Marin, M. Victoria Lopez-Ramon and Miguel A. AlvarezMerino, Carbon, 39 (7): 1415-1420, 2001.

[5] M. Molina-Sabio, F. Rodriguez-Reinoso, F. Caturala and M. J. Sellés; Carbon, 33 (8): 1105-1113, 1995.

[6] H. Benaddi, T. J. Bandosz, J. Jagiello, J. A. Schwarz, J. N. Rouzaud, D. Legras and F. Béguin, Carbon, Volume 38( 5): 669-674, 2000.

[7] E. F. Jaguaribe, L. L. Medeiros, M. C. S. Barreto and L. P. Araujo, Brazilian Journal of Chemical Engineering, 22(1): 41-47, 2005

[8] F. Caturla, M. Molina-Sabio and F. RodríguezReinoso, Carbon 29(7): 999-1007, 1991.

[9] J. J. Freeman, F. G. R. Gimblett, R. A. Roberts and K. S. W. Sing, Carbon, 26: 501, 1988.

[10] V. G. Serrano, F. S. Iniguez and C. V. Calahorro, Fuel 70: 1083, 1991.

[11] M. Kuroda, M. Yuzawa, Y. Sakakibara and M. Okamura, Water Research 22(5): 653, 1988. 